\title{
Comparing the mental health of housewives and day shift working women in Yazd County, Iran, 2010
}

\author{
Kholasezadeh Gh, $\mathrm{MD}^{1^{*}}$, Vaseghi $\mathrm{H}^{2}$, Ahmadi N, $\mathrm{MSc}^{3}$, Abedinzadeh M, MD ${ }^{4}$ \\ 1- Assistant Prof., Dept. of Psychiatry, Yazd Shahid Sadoughi University of Medical Sciences, Yazd, Iran. 2. Medical \\ student, Tehran university of medical sciences, Tehran, Iran. 3- Msc Clinical Psychology., Clinical Psychologist of \\ Counseling Center of Imam Hussain, Yazd, Iran. 4. Assistant Prof., Dept. of urology, Moradi hospital, Rafsanjan \\ University of Medical Sciences, Rafsanjan, Iran
}

\begin{abstract}
Received: August 2011, Accepted: November 2011

Background: There are studies reporting the adverse effects of working outside the house on women's mental health. As the mental health is affected by the structure and culture of each society, this study was conducted to compare the mental health of housewives and working woman in Yazd county, Iran (2010).

Materials and Methods: This cross-sectional study was done in Yazd county in 2010. Three hundred women were studied in two groups; group 1 consisted of 150 housewives and group 2 included 150 working women. The symptom checklist 90 (SCL-90) questionnaire was utilized for testing their mental health. SPSS-15 was used for analyzing the data.

Results: The results indicated that working women had better mental health than housewives $(\mathrm{p}=$ 0.0001). Moreover among the working women, the medical group had better mental health than the other groups $(p=0.006)$. There was no significant relationship between SCL-90 score and the number of children and also working history of women. But, there was a significant relationship between mental health of working women and their husbands' satisfaction of their jobs $(p=0.002)$.

Conclusion: Findings of this study showed that working women have better mental health than housewives. Also a significant association was found between the type of job and working women's mental health.
\end{abstract}

Key words: Mental Health, Working Women, Housewives

\section{Introduction}

According to sexual division of labor in family, men are considered as the breadwinners, whereas women should be responsible for houseworks. Traditional roles of women have changed, to some extent, by beginning of the industrial revolution, so they spend most of their time doing outdoor activities instead of doing just houseworks [1]. Because of the valuable role of women in inter-familial affairs, job stressors have adverse effects on them and other family members and would reduce their quality of life [2]. Numerous researches all over the world show that there is always a role conflict between women's indoor and outdoor activities and facing these problems is considered as a risk factor for their mental health. Recognition of these conflicts in order to reduce the problems induced by them shows the importance of this kind of researches [1]. Mental health is not just limited to description of causes of mental disorders; its main purpose is preventing occurrence of disturbances by creating factors which supplement healthy

\footnotetext{
corresponding author: Gholrasteh Kholasezadeh, Dept. of Psychiatry, Yazd Shahid Sadoughi University of Medical Sciences, Yazd, Iran.

Email: fa.net87@yahoo.com
} 
and normal life and also treating minute behavioral disorders in order to prevent severe mental disorders [3].

In a research, maternal and marital roles were shown to be natural and stress-free roles, whereas job was shown as an unnatural role with a lot of adverse effects on women [4]. In 1992, the United Nations reported occupational stress as the illness of $20^{\text {th }}$ century and after that world health organization reported it as an epidemic problem in the world [5]. Also, in a study done by Kawakami in 1999 occupational stressors were reported to be the strongest cause of psychological damages especially depression [6]. Some systematic researches reported that working women are healthier (physiologically or psychologically) than housewives [7-13], but in some other studies no significant statistical differences in satisfaction with marriage and family life or anxiety level between working and nonworking women was found [14,15]. It was shown in Spain in 2004 that unemployment is related to low level of mental health. According to Thomas research, men and women's job loss is related to their poor mental health and getting a job is directly related to mental health improvement [16].

Results of some studies reported a significant relation between the type of work and mental health. They also reported that having a decent job and doing it correctly causes an increase in self-confidence and would improve mental health [17, 18]. There are also beliefs based on this issue that women's jobs have negative effects on their maternal, marital and child caring roles [4,19], but there was no psychological or physiological differences between employed and unemployed women's children in Rosenfeld study [7]. The frequency of mental disorders in Iran is reported to be $21 \%$ [20]. The study of society's mental health is valuable for educational, treatment and prevention programs. Most of the women with psychiatric problems such as depression, anxiety, sleep disorders, etc referred to researchers' psychiatry clinics were housewives, and the prevalence of different types of psychiatric disorders among Yazdian women was reported to be $25 \%$ through Mohammadi's study [21]. Because of these reasons, inconsistent results in this context, the important role of women in the mental health of family, the effect of culture on psychiatric problems and lack of such studies, this study was done to survey the differences between mental health of working women and housewives of Yazd county in 2010 .

\section{Materials and Methods}

This is a cross sectional descriptive study which was done in Yazd county in 2010. Three hundred women were studied in two groups; group1 was composed of 150 housewives and group 2 consisted of 150 working women. Considering the significance level of $5 \%$ and $90 \%$ potency of the test and for attaining a minimum significant difference of $20 \%$ in mental health of women in the two groups sample size of 150 was calculated using the formula below:

$$
n=\frac{\left(Z_{\alpha}-Z_{\beta}\right)^{2} \cdot\left[P_{1}\left(1-P_{1}\right)+P_{2}\left(1-P_{2}\right)\right]}{\left(P_{1}-P_{2}\right)^{2}}
$$

The inclusion criteria included: 1) working women's minimal working period to be at least 6 months and housewives minimal marriage period to be at least 1 year. 2) age of respondents be between 20-50 years. 3) All of the workers be employed and working during daytime shifts. 
Exclusion criteria included: 1) women who had faced stressful situations during the last 3 months like the death of a family members. 2) All of the single employees, employees who were studying, women who were out of age range and those who had a history of psychiatric disorders. 3) Housewives who had another work apart from their house works and taking care of children. In order to include 150 housewives, we selected 6 health centers of Yazd county through cluster sampling method from the list of Yazd county health centers (Safaiieh, Maskan va shahr sazi, Shahedieh, Azadshahr and Fahadan were the chosen health centers). The researchers reffered to each center and selected 30 women randomly among the housewives who had referred to the center in order to vaccinate their children, for periodic checkup or health education.

Respondents were divided into three groups based on their jobs. Group 1: Physicians and nurses who were employed in Hospitals of Yazd county from 3 hospitals which were selected through cluster sampling method from the list of Yazd county hospitals (Hospitals: Rahnamoon, Shahid Sadooghi and Mortaz). Group2: Teachers who worked in Yazd county elementary, middle and high schools from 3 schools which were selected through cluster sampling method from the list of Yazd county schools. Group 3: Employees of Yazd county offices from 3 offices which were selected through cluster sampling method from the list of Yazd county offices (agriculture, transportation and health center offices were selected). Researchers reffered to these places and randomly selected 50 workers for each group. After communicating with them, explaining the importance of mental health, explaining the questionnaire itself for them and asking about some data that were needed (like their educational level, number of children and working history) a symptom checklist 90 (SCL-90) questionnaire was given to each person. SCL-90 is a psychological self-report inventory. The 90 items in the questionnaire are scored on a five-point Likert scale, indicating the rate of occurrence of the symptom during the time reference. SCL-90 has been proved to be an adequate psychiatric research instrument [22]. The test measures 9 primary symptoms dimensions and each symptom include 6-12 questions and the average score for questions of each 9 domains is computed. The average score of SCL-90 test could be between 0-4; mental health level will decrease by the increase in test score [22, 23].

In this study, samples with $0-1$ average score which was considered mentally healthier were compared with samples with more than 1 average scores statistically. We asked about working women spouses' satisfaction of their working with an extra question at the end of the questionnaire. Then we collected the data and analyzed them with SPSS-15 by using chi-square test.

Table 1: Comparing mental health of housewives and working women

\begin{tabular}{|c|c|c|c|c|c|c|}
\hline \multirow[b]{3}{*}{ job } & \multicolumn{4}{|c|}{ Mental health mean score* } & \multirow{2}{*}{\multicolumn{2}{|c|}{ total }} \\
\hline & \multicolumn{2}{|c|}{$\mathbf{0}-1$} & \multicolumn{2}{|c|}{$1<$} & & \\
\hline & No & Percent & No & Percent & No & Percent \\
\hline Housewife & 63 & 42 & 87 & 58 & 150 & 100 \\
\hline Working women & 104 & 69.3 & 46 & 30.7 & 150 & 100 \\
\hline Total & 167 & 55.7 & 133 & 44.3 & 300 & 100 \\
\hline
\end{tabular}

Chi-square $=22.7, \mathrm{df}($ degree of freedom $)=1, \mathrm{p}$-value $=0.0001$

* -Mental health mean score less than 1 shows a better situation. 


\section{Results}

In this research, 300 married women were studied in 2 groups (group 1: 150 housewives, group2: 150 employees). According to table 1 working women had better mental health compared with the housewives. Considering the educational level of samples, there was a significant association between mental health and the educational level of housewives ( $\mathrm{p}$-value $=$ 0.004).

But in the working group there was not any significant association. There was a significant association between mental health and the type of job. In this regard, the medical group had better mental health among the working women.

Table 2: Comparing mental health of respondents based on the type of their job.

\begin{tabular}{|c|c|c|c|c|c|c|c|c|}
\hline \multirow[b]{3}{*}{ Test score } & \multicolumn{6}{|c|}{ Job } & & \\
\hline & \multicolumn{2}{|c|}{ Medical group } & \multicolumn{2}{|c|}{ Teacher } & \multicolumn{2}{|c|}{ employee } & \multicolumn{2}{|c|}{ total } \\
\hline & No. & Percent & No. & Percent & No. & Percent & No. & Percent \\
\hline 0 - 1 & 43 & 41.3 & 32 & 30.8 & 29 & 27.9 & 104 & 100 \\
\hline $1<$ & 7 & 15.2 & 18 & 39.1 & 21 & 45.7 & 46 & 100 \\
\hline Total & 50 & 100 & 50 & 100 & 50 & 100 & 150 & 100 \\
\hline
\end{tabular}

Table3: Comparing health parameters between housewives and workers

\begin{tabular}{|c|c|c|c|c|c|c|c|c|}
\hline \multirow{3}{*}{$\begin{array}{l}\text { Studied } \\
\text { criteria }\end{array}$} & \multirow{3}{*}{$\begin{array}{l}\text { Studied } \\
\text { group }\end{array}$} & \multicolumn{4}{|c|}{ Mental health mean score } & \multirow[b]{3}{*}{ p-value } & \multirow[b]{3}{*}{ df } & \multirow{3}{*}{$\begin{array}{l}\text { Chi- } \\
\text { square }\end{array}$} \\
\hline & & \multicolumn{2}{|c|}{$0-1$} & \multicolumn{2}{|c|}{$1<$} & & & \\
\hline & & No. & Percent & No. & Percent & & & \\
\hline \multirow{3}{*}{ Hostility } & Housewives & 80 & 53.3 & 70 & 46.7 & \multirow{3}{*}{0.00001} & \multirow{3}{*}{1} & \multirow{3}{*}{14.81} \\
\hline & workers & 112 & 74.7 & 38 & 25.3 & & & \\
\hline & Housewives & 72 & 48 & 78 & 52 & & & \\
\hline \multirow[t]{2}{*}{ Anxiety } & workers & 114 & 76 & 36 & 24 & \multirow[t]{2}{*}{0.0001} & \multirow[t]{2}{*}{1} & \multirow[t]{2}{*}{24.9} \\
\hline & Housewives & 58 & 38.7 & 92 & 61.3 & & & \\
\hline \multirow{3}{*}{$\begin{array}{l}\text { Depression } \\
\text { Interpersonal } \\
\text { sensitivity }\end{array}$} & workers & 89 & 59.3 & 61 & 40.7 & \multirow[t]{2}{*}{0.0003} & \multirow[t]{2}{*}{1} & \multirow[t]{2}{*}{12.82} \\
\hline & Housewives & 63 & 42 & 87 & 58 & & & \\
\hline & workers & 93 & 62 & 57 & 38 & 0.0005 & 1 & 12.01 \\
\hline \multirow{3}{*}{$\begin{array}{l}\text { Obsessive- } \\
\text { compulsive }\end{array}$} & Housewives & 38 & 25.3 & 112 & 74.7 & \multirow[b]{2}{*}{0.00004} & \multirow[b]{2}{*}{1} & \multirow[b]{2}{*}{16.59} \\
\hline & workers & 72 & 48 & 78 & 52 & & & \\
\hline & Housewives & 117 & 78 & 33 & 22 & \multirow[b]{2}{*}{0.004} & \multirow[b]{2}{*}{1} & \multirow[b]{2}{*}{8.04} \\
\hline Psychoticism & workers & 135 & 90 & 15 & 10 & & & \\
\hline \multirow{2}{*}{$\begin{array}{l}\text { Paranoid } \\
\text { ideation }\end{array}$} & Housewives & 53 & 35.3 & 97 & 64.7 & \multirow[b]{2}{*}{0.0005} & \multirow[b]{2}{*}{1} & \multirow[b]{2}{*}{16.4} \\
\hline & workers & 88 & 58.7 & 62 & 41.3 & & & \\
\hline \multirow[t]{2}{*}{ Somatization } & Housewives & 55 & 37.5 & 95 & 63.3 & \multirow{3}{*}{0.0001} & & \\
\hline & workers & 99 & 66 & 51 & 34 & & 1 & 25.8 \\
\hline Phobic & Housewives & 114 & 76.5 & 35 & 23.5 & & & \\
\hline anxiety & workers & 132 & 88 & 18 & 12 & 0.009 & 1 & 6.8 \\
\hline
\end{tabular}


There was no significant association between SCL-90 score and number of children and also occupational history. After analyzing the data with chi-square test there was a significant difference between housewives and working women in all of the health parameters. For 64 (61.5\%) working women husband's support was reported. This group of working women had better mental health than those who did not have this support.

Table 4: Association between mental health of working women and their husband satisfaction

\begin{tabular}{|c|c|c|c|c|c|c|c|c|c|c|}
\hline \multirow[b]{3}{*}{ Test Score } & \multicolumn{8}{|c|}{ Satisfaction } & & \\
\hline & \multicolumn{2}{|c|}{ Quite } & \multicolumn{2}{|c|}{ Somewhat } & \multicolumn{2}{|c|}{ Very low } & \multicolumn{2}{|c|}{ Any } & \multicolumn{2}{|c|}{ Total } \\
\hline & NO & $\mathrm{P}$ & NO & $\mathrm{P}$ & $\mathrm{NO}$ & $\mathrm{P}$ & NO & $\mathrm{P}$ & $\mathrm{NO}$ & $\mathrm{P}$ \\
\hline 0 - 1 & 64 & 61.5 & 34 & 34.6 & 2 & 1.9 & 2 & 1.9 & 104 & 100 \\
\hline $1<$ & 21 & 45.7 & 18 & 39.1 & 4 & 8.7 & 3 & 6.5 & 46 & 100 \\
\hline Total & 85 & 56.7 & 54 & 36 & 6 & 4 & 5 & 3.3 & 150 & 100 \\
\hline
\end{tabular}

Chi-square $=7.4$

$\mathrm{df}=3$

P-value $=0.002$

Chi-square test showed a significant association between mental health of working women and their husbands' satisfaction $(\mathrm{p}$-value $=0.002)$

\section{Discussion}

Mental health of women has an essential role in the society and the family, so it should be placed on the top of the health programs. Therefore in order to check the effective factors on mental health of women this study was performed. According to other studies, different theories about positive or negative effects of occupation on mental health of women have been made $[4,7,11,16,17]$. In this study, housewives' SCL-90 scores were significantly more than working women. In other words, working women were mentally healthier than housewives. This result is in consistency with some other studies $[7,11$, 17], but does not agree with studies that demonstrate adverse effects of occupation [4, 16]. The increase in social contact and social support on the job may reduce the risk of illnesses and psychiatric disorders among working women, in fact their higher confidence (due to the financial factors) could be the reason for this fact. Moreover, Waldron found that housewives reported more chronic illnesses than employed women and were more likely to rate their health as poor or fair compared to the employed women [17]. Although there are many working stressors for women in the society, working women were mentally healthier according to the results of our study and these stressors did not have a significant effect on their mental health. It might be explained by the fact that through the revolution in the culture and women's tendency to work outside the house, unemployment is a greater stress itself than working stressors. Furthermore, housewives are at home most of the time and do repetitious works that could increase the feeling of uselessness about them.

In this study, the association between the type of job and mental health was also studied. According to the results, test scores of employees were the highest and physicians and nurses' had the lowest scores. Therefore among the employed women physicians and nurses had better mental 
health. Although nurses and Physicians face more risk factors due to their higher working hours and severe working stressors, through results of this study, they were shown to be mentally healthier. Maybe it could be explained by their work satisfaction, high occupational level, and social role of them in the society or may be as they work for the people's health and lives they are more satisfied with their jobs. In a study about work stresses of Ahvazian women, more work dissatisfaction was seen between the laborers. the study mentioned high social status as a factor which could reduce stress [24]. Furthermore, the adverse effects of work load on women's health were found in another study [25].

As working women have social roles in addition to their role as mothers or wives, they usually have problems with their husbands. Therefore, the relation between husband's satisfaction and their mental health was studied. According to the results, test scores of women whose husbands were dissatisfied with their job test score were the highest and in women whose husbands were satisfied with their jobs were the lowest. In other words, working women's mental health is in direct positive association with husbands' satisfaction. It could be hypothesized that husbands' satisfaction could increase their cooperation in family and houseworks, therefore, it would reduce women's family role stressors [1]. This stress reduction could be an effective factor in improving their mental health. Having a family increases the women's responsibilities and problems, but as they face individual or social problems often husbands and sometimes children protect them mentally and emotionally which has an important role in reducing their stress and depression. According to the results of this study, there was no significant association between mental health and the number of children. Studies conducted by Ahmadnia and Lam also showed the same results $[9,26]$. In this study, the relations between samples' level of education and mental health was also studied. Results showed that test scores of uneducated housewives were the highest, but among housewives with bachelor's degree and higher educational levels these scores were the lowest. In other words, by increasing educational level of housewives, their mental health would also increase. Test scores of under high school diploma employed women were the highest, while that of women with doctorate levels were the lowest. But there was no significant association between mental health of working women and their educational level. It shows the essential effect of working on mental health of women. Ahmadnia also demonstrated the same results in his research [9].

Finally, each of the parameters of mental health test rate between housewives was significantly higher than the working women. Between the health parameters, the rate of obsession and compulsion in both housewives and employed groups was more than the other parameters. In the study, we did not measure the effect of culture on the difference between mental health of housewives and working women. This factor could be measured in future studies. Also, some studies could be conducted in order to determine factors which cause better mental health in working women than housewives.

\section{Conclusion}

Findings of this study showed that working women have better mental health than housewives, and between working women medical group had better mental health than both teachers and employees groups. Furthermore, there was a significant 
association between mental health of working women and their husband's satisfaction. But, according to the results, no significant association between mental health of working women and the number of their children and also working history was found.

\section{Acknowledgment:}

We would like to thank Dr Kobra Abedinzadeh, Firoozgar Clinical Research Development Center (FCRDC), Dr SeyedMohammad Fereshtehnejad Dr Mohammad Aboohoseini Tabari, Dr hoseyn phalah zade and Dr hamidreza gafaryeh which helped us with this research.

Conflict of interest: Non declared

\section{References}

1. Maghsoudi S, Bostan Z. Study of the problems caused by concurrency of domestic and social roles of employed women in Kerman city. Study of women magazine 2004; 5(2):129-150. (Persian).

2. Souri H, Saadabad AR. Occupational stresses in women. Hakim magazine 2004; 6(1):65-72. (Persian).

3. Shamlou S (2009). Mental health. $1^{\text {nd }}$ ed. Tehran: Roshd. P18.

4. Barnett RC. Women and multiple roles: myths or reality. Harv Rev Psychiatry 2004; 12(3):158-64.

5. Tangri RP (2003). What Stress Costs. Halifax: Chrysalis Performance Strategies Inc.

6. Kawakami N, Haratani T. Epidemiology of job stress and health in Japan: review of current evidence and future direction. Ind Health 1999; 37(2):174-86.

7. Rosenfeld JA. Maternal work outside the home and its effect on women and their families. J Am Med Womens Assoc 1992; 47(2):47-53.

8. Artazcoze L, Borell C, Cortes I, Benach J, Imma C. Women family demands and health: A study of employed women in Sweden. Scand J Public Health 2008; 36(1):7-21.

9. Ahmad- Nia S. Women's work and health in Iran: a comparison of working and nonworking mothers. Soc Sci Med 2002; 54(5):753-65.

10. Melchior M, Caspi A, Milne BJ, Danese A, Poulton R, Moffitt TE. Work stress Precipitates depression and anxiety in young, working women and men. Psychol Med 2007; 37(8):1119-29.

11. La Rosa JH. Women, work, and health: employment as a risk factor for coronary heart disease. Am J Obstet Gynecol 1988; 158(6 pt 2):1597-602.

12. Herman H. long- term outcome and rehabilitation. Curr Opin Psychiatry 1998; 11:175-182.

13. Devries MW, Wilkerson B. Stress, work and mental health: A global perspective. Acta Neuropsychiatrica 2003; 15(1):44.

14. Park C. Sex-role attitudes and employment status as predictors of perceived life satisfaction among married women in Korea. Korea J Popul Dev 1991; 20(1):23-45.

15. Mukhopadhyay S, Dewanji A, Majumder PP. Working status and anxiety levels of urban educated women in Calcutta. Int $\mathbf{J}$ Soc Psychiatry 1993; 39(3):200-7.

16. Thomas C, Benzeval M, Stansfeld SA Employment transitions and mental health: an analysis from the British household panel survey. J Epidemiol Community Health. 2005; 59(3):243-9.

17. Waldron I. Employment and women's health: an analysis of causal relationships. Int $\mathbf{J}$ Health Serv 1980; 10(3):435-54.

18. Lotf Abadi H. charecteretics of youths and their occupational identity. Occupation and society magazine 2002; 47:27. [Persian].

19. Staland- Nyman C, Alexanderson K, Hensing G. Associations between strain in domestic work and self-rated health: a study of employed women in Sweden. Scand J Public Health 2008; 36(1):7-21.

20. Artazcoz L, Benach J, Borrell C, Cortes I. Unemployment and mental health: understanding the interactions among gender, family roles, and social class. Am J Public Health 2004; 94(1):82-8.

21. Mohammadi MR, Bagheri Yazdi SA, Rahgozar $\mathrm{M}$, et al. Epidemiology of psychiatric disorders in Yazd county in 2001. Yazd Shahi Sadooghi 
university of medical sciences magazine 2003; 11(3):28-37. [Persian].

22. Holi M. Assessment of psychiatric symptoms using the SCL-90. Unpublished Science, Medical Faculty, Helsinki 2003.

23. Derogatis LR, Rickels K, Roch AF. The SCL90 and the MMPI: a step in the validation of a new selfreport scale. Br J Psychiatry 1976; 128:280-9.

24. Souri H, Hatami Saadabad AR. Occupational stress in employed women in Ahvaz. Hakim magazine 2003; 6(1):27-44. [Persian].

25. Gjerdingen $\mathrm{D}$, McGovern $\mathrm{P}$, Bekker $\mathrm{M}$, Lundberg U, Willemsen T. Women's work roles and their impact on health, well-being, and career: comparisons between the United States, Sweden, and The Netherlands. Women Health. 2000; 31(4):1-20.

26. Lam LT. Aggression exposure and mental health among nurses. Australian Journal for the advancement of mental health 2002; 1(2):1-12. 